\title{
RODOLFO CASAMIQUELA G.
}

(1932-2008)

En un comunicado de escasas palabras, la Asociación Paleontológica Argentina informó el fallecimiento de su socio vitalicio, Dr. Rodolfo Casamiquela, el día 5 de diciembre del 2008. Rodolfo fue, en cambio, un hombre de muchísimas palabras.

Antes que un científico de la estatura que alcanzó era una persona que vivió intensamente. Lo hizo con sus anécdotas, con el profundo sentimiento de pertenencia con su natal Río Negro y su Patagonia, nacido en Ingeniero Jacobacci, fallecido en Cipolleti. Entonaba, sin pausa y con agradable voz, una tras otra alguna de las cientos de canciones folclóricas de su país, mientras recorríamos el desierto del norte chileno. Político de izquierda sin estridencias, discursos ni aprovechamientos, no transaba con sus principios ni buscaba convencer a nadie.

Con una barbilla y una nariz agresivas, labios delgados y tercos, proclives a la sonrisa maliciosa, a veces parecía ser ofensivo con sus planteamientos. Diría que no, que fue sencillamente un hombre franco; además de apasionado, inteligente, estudioso e imaginativo. Un hombre duro a veces y tenía que serlo porque fue resistido y atacado por situaciones puntuales e incluso se le negó el reconocimiento de 'Mayor Notable' por parte del Congreso Nacional Argentino. También hubo manifestaciones mapuches en su contra, entre otras razones porque planteaba que éstos habían agredido históricamente a los tehuelches.

Amigo de las bromas sin consecuencias oscuras. Alguna vez se acercó a algún mapuche distraído en la Plaza de Armas de Santiago y le habló no sólo en su idioma, sino también en su acento. Había que ver entonces la cara del interpelado.

Era un esgrimista de las palabras. Paleontólogo de Vertebrados, Antropólogo con especialidad en etnología patagónica y en las lenguas indígenas regionales. La muerte lo sorprendió como investigador del Centro Nacional Patagónico del CONICET de Puerto Madryn. En Argentina fue Premio Nacional de Antropología, también de Biología; Profesor Emérito de la Universidad Nacional de la Patagonia Austral, Presidente de la Fundación Ameghino, propuesto como Doctor Honoris Causa y profesor de varias universidades en Chile. El año

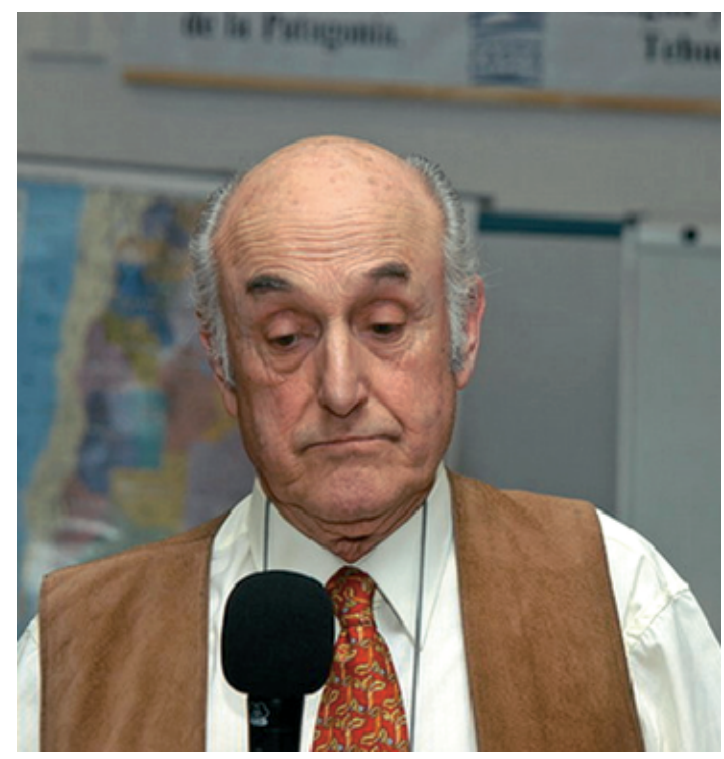

2006 fue distinguido con el Premio Konex en la disciplina de Antropología y Arqueología Cultural que destacó a Casamiquela como una de las cien personalidades del país más destacadas en la Ciencia durante la última década.

Cuando llegó a Chile convenció con su palabra, sin hacer alardes, y en la práctica inició los estudios de Paleontología de Vertebrados en el país. Su especialidad era la Icnología, pero su visión era la de un naturalista y su capacidad la de un profesional. Para mí siempre fue de mucho impacto la certeza con que definía los organismos fósiles que encontrábamos en terreno. Las clasificaciones de paleontólogos posteriores coincidieron con las que él hizo prácticamente en el mismo momento en que recolectó la pieza. Paleontólogo de ojo agudo 'desenterró' muchos fósiles con su vista, donde nadie los veía. Publicó en Chile una descripción de la fauna de vertebrados de Pichasca, de las pisadas de dinosaurios de las Termas de Pichasca, el descubrimiento del primer reptil volador mesozoico, los antecedentes del primer cocodrilo primitivo del Triásico; las primeras huellas pliocenas de caballo.

Cuando Rodolfo estuvo en Chile era un autodidacta, a veces discutido por sus colegas trasandinos, especialmente por su estilo. Aquí desarrolló 
una parte importante de sus actividades, destacándose su doctorado en Ciencias con mención en Biología en la Universidad de Chile. También incursionó en Antropología como fue el caso de las excavaciones de San Vicente de Tagua Tagua.

Después se fue a su país, donde siempre quiso estar: en su Patagonia. Su obra fue prolífica, respetada, generosa y también discutida. Más de 400 publicaciones científicas y de divulgación y más de 20 libros describen sus trabajos y a ellos se agrega la fundación del Museo de Jacobacci. Sus libros incluyen una gramática tehuelche y uno sobre la toponimia de la Patagonia.
Hace décadas que desapareció de los escenarios donde yo me desempeñaba. Al irse de Chile prosiguió su carrera en su país con viajes esporádicos a Chile. Nunca más lo volví a ver y hace un año lo busqué, sin éxito, en su pueblo.

Ahora tomó el camino más largo. Yo creo que ni la eternidad será capaz de satisfacer su curiosidad, como tampoco podrá ser olvidado por los que lo conocimos y fuimos sus amigos. Un gran abrazo amigo Rodolfo, sin lágrimas, pero con la pena profunda de las despedidas definitivas.

Guillermo Chong Díaz

Diciembre, 2008. 